\title{
Epidermal growth factor receptors, testosterone levels and parotid gland changes in rats infected with Trypanosoma cruzi
}

\author{
Kezia LH Aguirre', José B Alves ${ }^{1,4}{ }^{+}$, Gerluza AB Silva1, Jarbas E Cardoso², Silvane MF Murta ${ }^{3}$, \\ Anderson J Ferreira ${ }^{1}$
}

'Departamento de Morfologia, Instituto de Ciências Biológicas ²Departamento de Análises Clínicas e Toxicológicas, Faculdade de Farmácia, Universidade Federal de Minas Gerais, Av. Antônio Carlos 6627, 31270-010 Belo Horizonte, MG, Brasil ${ }^{3}$ nstituto de Pesquisa René Rachou-

Fiocruz, Belo Horizonte, MG, Brasil ${ }^{4}$ Laboratório de Biopatologia e Biologia Molecular, Universidade de Uberaba, Uberaba, MG, Brasil

It has been demonstrated that parotid glands of rats infected with Trypanosoma cruzi present severe histological alterations; changes include reduction in density and volume of the acini and duct systems and an increase in connective tissue. We evaluated the association between morphological changes in parotid glands, circulating testosterone levels and epidermal growth factor receptor (EGF-R) expression in experimental Chagas disease in rats. Animals at 18 days of infection (acute phase) showed a significant decrease in body weight, serum testosterone levels and EGF-R expression in the parotid gland compared with a control group. Since decreases in body weight could lead to a reduction in circulating testosterone concentration, we believe that the reduction in EGF-R expression in parotid glands of infected rats is due to alterations in testosterone levels and atrophy of parotid glands is caused by changes in EGF-R expression. Additionally, at 50 days (chronic phase) of infection parotid glands showed a normal histological aspect likely due to the normalization of the body weight. These findings suggest that the testosteroneEGF-R axis is involved in the histological changes.

Key words: parotid glands - histological alterations - Chagas disease - testosterone - EGF-receptor

Chagas disease (South American trypanosomiasis), caused by the hemoflagellate Trypanosoma cruzi (Chagas 1909), is one of the most prevalent and serious diseases in South America (WHO 2000). The parasites can infect, in particular, the heart, esophagus and intestine (Vieira 1961, Koberle 1968, Pereira et al. 2006). We have previously reported that submandibular salivary glands from rats infected with $T$. cruzi demonstrate accelerated acinar development and delayed ductal maturation, characteristics more evident in developing granular ducts (Alves \& Machado 1980); these changes may be explained by a lower expression of DNA synthesis genes (Alves et al. 2008).

Recently we found morphological alterations in granular convoluted tubule cells and lower epidermal growth factor (EGF) in immunolabelled cells in submandibular glands of infected rats (Moreira et al. 2008). In contrast, studies with parotid glands reveal a significant reduction of density and volume of the acini and duct systems, as well as a significant increase in the amount of connective tissue present after 18 days of infection (Silva et al. 2000). However, the mechanisms involved in these alterations are still unclear.

It has been proposed that retarded sexual maturity, characterized by lower circulating testosterone levels due

Financial support: FAPEMIG, PAPE

+ Corresponding author: propg.pr@uniube.br

Received 21 January 2009

Accepted 7 July 2009 to the lower body weight of these animals (Courout et al. 1970), could contribute to the morphological changes observed in infected rats' glands (Silva et al. 2000), as testosterone can regulate the expression and synthesis of EGF (Kasayama et al. 1990). Further, decreased EGF expression and receptors driven by the lack of testosterone may contribute to atrophy of the parotid gland and proliferation of connective tissue (Silva et al. 2000).

The current study was performed to verify the mechanisms underlying histological changes observed in parotid glands in experimental Chagas disease in rats. Specifically, we measured circulating testosterone levels and quantified the amount of EGF receptors (EGF-R) in these glands along with those of non-infected rats.

\section{MATERIALS AND METHODS}

Experimental development of Chagas disease Holtzman male rats, aged 27-29 days, with an average weight of $90 \mathrm{~g}$ were used ( $\mathrm{n}=6$ for each group). To induce experimental Chagas disease, the animals were inoculated intraperitoneally (i.p.) with $0.15 \mathrm{~mL}$ of mouse blood containing approximately 300,000 trypomastigotes (Y strain) of $T$. cruzi. This strain was previously isolated from a patient with Chagas disease (Silva \& Nussenzweig 1953) and has been maintained in mice by repeated blood passages every seven days. Infection of rats was confirmed by the presence of living trypomastigotes in the blood of all animals 10 days after inoculation as previously described by Brener (1962). Twelve animals were used as controls and received $0.15 \mathrm{~mL}$ of $0.9 \% \mathrm{NaCl}$ i.p. The rats were weighed and killed at 18 and 50 days after inoculation.

This animal study was designed according to the Brazilian Guidelines (Resolution 196 of the National 
Health Council 1996) and the protocol was approved by the Research Ethical Committee of Federal University of Minas Gerais (protocol 141/07).

Histological and histoquantitative study - Infected and control rats were anesthetized with $10 \mathrm{mg} / \mathrm{Kg}$ xylazine (Bayer, Istanbul, Turkey) and $60 \mathrm{mg} / \mathrm{Kg}$ ketamine hydrochloride (Parker Davis, Istanbul, Turkey). The right and left parotid glands were removed, weighed and immersed in buffered neutral formalin for $48 \mathrm{~h}$. After a brief washing in running tap water, the glands were dehydrated, embedded in paraffin and sectioned at $6 \mu \mathrm{m}$. The sections were stained with hematoxylin and eosin. The gland images were obtained using a capture plate and light microscope (Olympus BX 50).

Serum testosterone levels - After parotid glands removal, blood samples was collected by cardiac puncture from the left ventricle in eppendorf tubes. The serum was separated by centrifugation and stored at $-20^{\circ} \mathrm{C}$. Serum testosterone levels were measured using a commercially available radioimmunoassay kit (Testosterone Maia Kit/Biochem Immunosystems Italia SPA) according to the manufacturer's protocol. The minimum sensitivity of this kit is $0.064 \mathrm{ng} / \mathrm{L}$.

Quantification of $E G F-R$ - The glands were dissected free from connective tissue, minced with razor blades into small fragments and homogenized in a $5 \%(\mathrm{w} / \mathrm{v})$ suspension in a Potter glass (Thomas, Philadelphia, PA, B38263) with a fitted Teflon pestle turning at 1,500 rpm using a stirring apparatus (Mod. 4201, Dormeyer Corp Chicago, IL) for three strokes with intervals of $1 \mathrm{~min}$ in the ice bath. The homogenizing medium consisted of $340 \mathrm{mM}$ sucrose and $0.5 \mathrm{mM}$ ethylenediaminetetraacetic acid in $10 \mathrm{mM}$ HEPES buffer, $\mathrm{pH}$ 7.4. The homogenate was filtered to remove fibrous connective tissue and insoluble particles. Total protein concentration of each sample was measured according to the Bradford method (Bradford 1976). The samples $(100 \mu \mathrm{g}$ total protein $/ 20 \mu \mathrm{L}$ ) were boiled for $5 \mathrm{~min}$ at $100^{\circ} \mathrm{C}$ and loaded onto an $8 \%$ SDS-PAGE gel for electrophoresis. After electrophoresis, gels were stained with Coomassie Blue. Proteins were transferred to a nitrocellulose membrane, blocked with TBST buffer (10 mM Tris base, $150 \mathrm{mM}$ $\mathrm{NaCl}, 0.05 \%$ Tween $20, \mathrm{pH} 7.4$ ) containing $1.6 \%$ casein at $4^{\circ} \mathrm{C}$ and under agitation. Blots were then incubated overnight with a polyclonal sheep anti-rat EGF-R antibody (1:2,000; Sigma-Aldrich) at $4^{\circ} \mathrm{C}$. Membranes were washed three times in TBST buffer and exposed to the secondary antibody (donkey anti-sheep IgG conjugated with alkaline phosphatase at 1:10,000 dilution) for $1 \mathrm{~h}$ at RT under agitation. Finally, blots were revealed by chemiluminescence with an ECL kit (Western Blot Chemiluminescence Reagent Plus - NEN Life Science Products), scanned and quantified by densitometry.

Statistical analysis - The difference between evaluated parameters in the groups was tested by using the ANOVA test followed by Tukey's test. The data distribution of all groups passed the Kolmogorov-Smirnov test of normality. All analyses were carried out in triplicate and significance was accepted when $\mathrm{p}<0.05$.

\section{RESULTS}

In accordance with previous studies, parotid glands from infected rats with $T$. cruzi (acute phase) showed a reduced density and volume of acini, as well as an increase in connective tissue (Fig. 1A, B). However, after 50 days of infection no histological differences were observed between infected and control groups (Fig. $1 \mathrm{C}, \mathrm{D})$. In addition, at 18 days of infection, infected rats showed a significant decrease in both body weight $(150.1 \pm 2.97$ v.s. $68.5 \pm 5.12 \mathrm{~g}$ in infected rats, $\mathrm{p}<0.05)$ (Fig. 2A) and relative parotid gland weight $(408.3 \pm$ 26.5 v.s. $265.0 \pm 36.7 \mathrm{mg}$ of gland $/ \mathrm{g}$ of body in infected rats, p < 0.05) (Fig. 2B) compared with non-infected rats. No significant changes in these parameters were observed at 50 days of infection $(287.0 \pm 3.41$ v.s. 275.6 $\pm 5.52 \mathrm{~g}$ of body weight in infected rats and $655.0 \pm$ 113.2 v.s. $566.7 \pm 113.9 \mathrm{mg}$ of gland/g of body) of glandular weight in infected rats).

To investigate the relationship between histological alterations in parotid glands and testosterone and EGF$\mathrm{R}$ levels in rats with experimental Chagas disease, we measured circulating testosterone concentration and EGF-R expression in the glands. Serum testosterone levels in animals at 18 days of infection were significantly lower than in the control group $(0.532 \pm 0.152$ v.s. $0.030 \pm 0.008 \mathrm{ng} / \mathrm{mL}$ in infected rats, $\mathrm{p}<0.05$ ) (Table). After 50 days of infection, no significant difference in

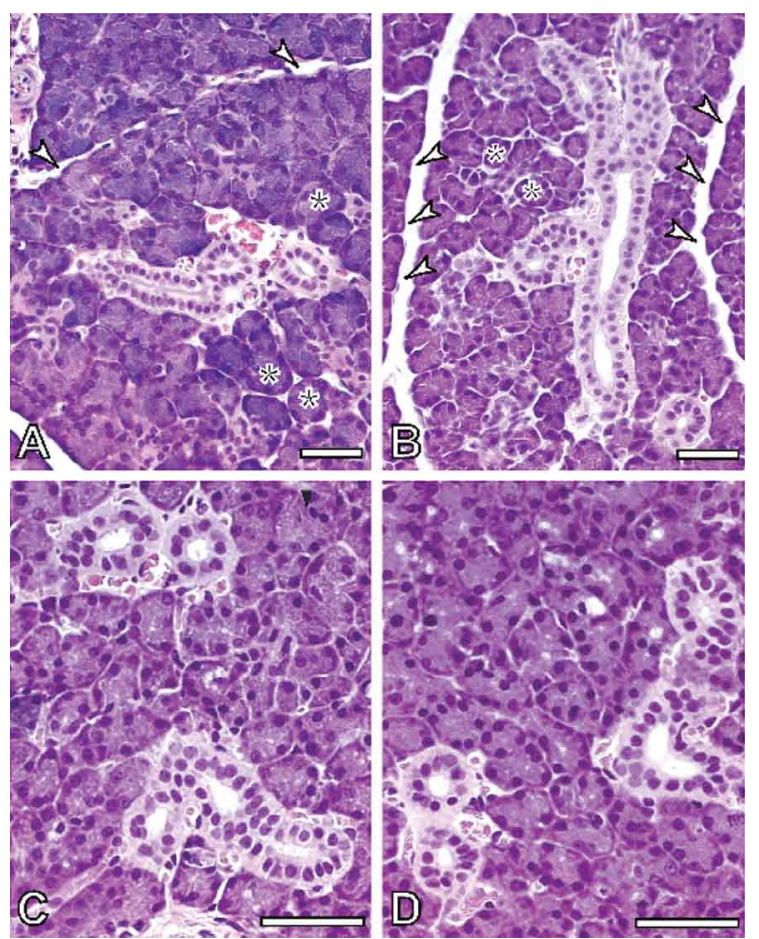

Fig. 1: histological aspect of parotid glands. Control (A) and infected (B) animals 18 days after inoculation. Note the reduction in acini dimension $(*)$ and increase of connective tissue area (arrow heads) in infected animals. Similar histological aspects were found in control (C) and infected (D) rats after 50 days of infection. Bar $=50 \mu \mathrm{m}$. 

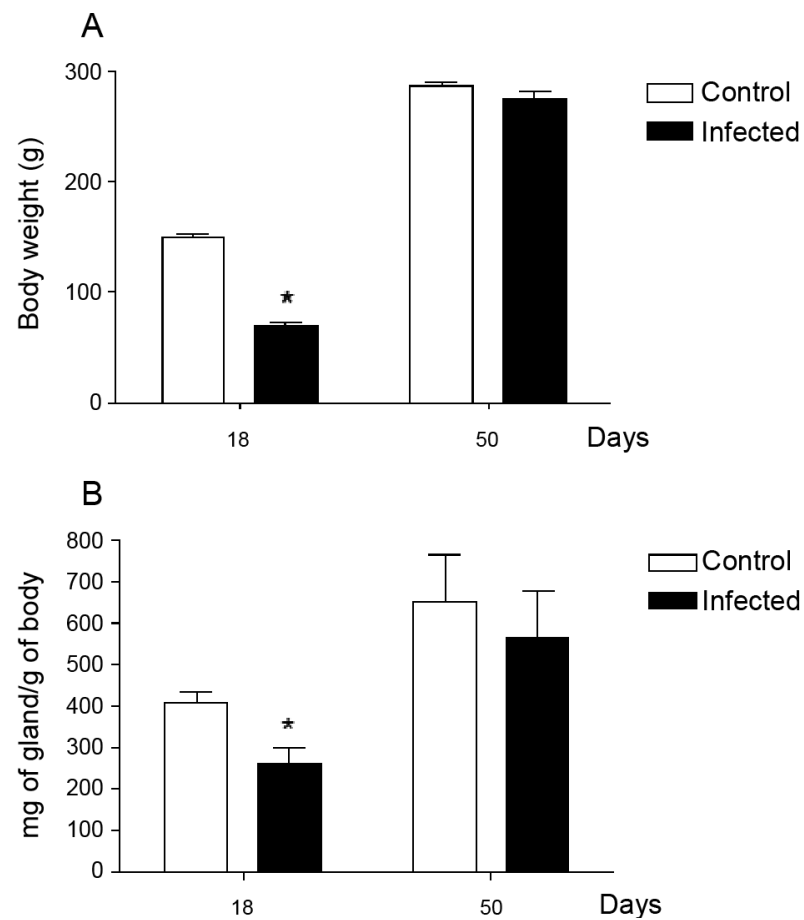

Fig. 2: body weight (A) in control and infected rats (asterisks mean $\mathrm{p}<0.0001$, Student's $t$-test). Relative parotid gland weight (B) in control and infected rats after 18 or 50 days of infection (asterisks mean $\mathrm{p}<0.005$, Student's $t$-test).
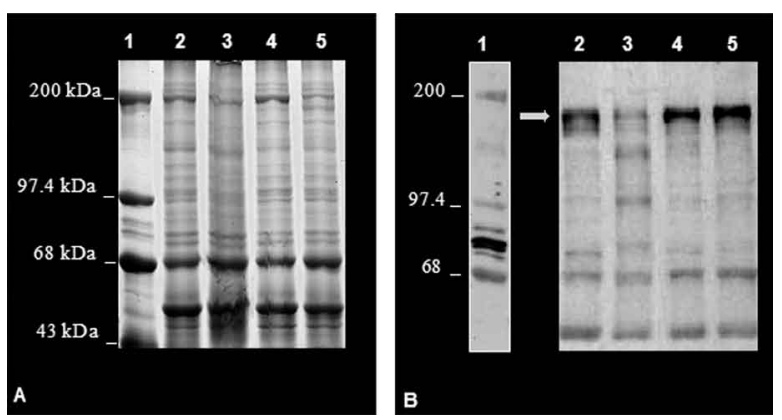

Fig. 3: epidermal growth factor receptors (EGF-R) levels in parotid gland extract of control and infected rats after 18 or 50 days of infection. Representative electrophoresis of total proteins (A) and of western blotting membrane (B) using an antibody against EGF-R. The arrow points to $170 \mathrm{KDa}$ bands that correspond to EGF-R. Lane 1: marker; 2: control (18 days); 3: infected (18 days); 4: control (50 days); 5: infected (50 days).

testosterone levels was observed between control $(4.740$ $\pm 0.607 \mathrm{ng} / \mathrm{mL})$ and infected groups $(3.800 \pm 0.491 \mathrm{ng} /$ $\mathrm{mL}$ ). Furthermore, western blotting analysis revealed that EGF-R levels in infected rats at 18 days of infection were statistically different than observed in control rats. However, at 50 days of infection no significant changes were viewed between infected and control rats regarding EGF-R levels (Figs 3, 4).

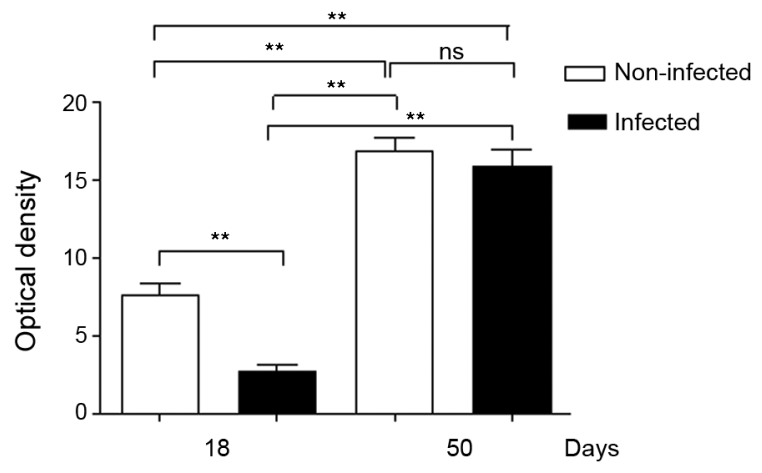

Fig. 4: analysis of epidermal growth factor receptors (EGF-R) expression (170 kDa band). Differences in protein quantity. ns: no significant. Asterisks mean $\mathrm{p}<0.001$.

TABLE

Circulating testosterone levels in control and infected rats after 18 or 50 days of infection

\begin{tabular}{lcc}
\hline & \multicolumn{2}{c}{ Infection period } \\
\cline { 2 - 3 } Days & \multicolumn{1}{c}{18} & 50 \\
\hline Control & $0.325 \pm 0.1527^{a}$ & $4.740 \pm 0.6076$ \\
Infected & $0.0300 \pm 0.0083$ & $3.800 \pm 0.4916$ \\
\hline
\end{tabular}

$a: \mathrm{p}=0.0036$ compared with control group at the same period of infection (Student's $t$-test).

\section{DISCUSSION}

The most significant finding in the present study is that infection with $T$. cruzi is associated with a significant decrease in both plasma testosterone levels and EGF-R expression in parotid glands of rats during the acute phase (at 18 days of infection) of experimental Chagas disease. It has been previously demonstrated that parotid glands of rats at 18 days of infection show a significant reduction in the volume of acini with a concomitant increase in the volume of stroma and connective tissue (Silva et al. 2000). Similar histological changes were observed in parotid glands of rats after orchiectomy (Jezek et al. 1996), suggesting that testosterone is involved in the development and maintenance of parotid gland structure in rats.

Body weight plays an important role in sexual maturity (Courout et al. 1970). A delay in developing testis is reflected in circulating testosterone levels. Accordingly, our results show a significant decrease in body weight of rats after 18 days of infection with concomitant reduction in plasma testosterone levels. These findings are in accordance with those of Tavares et al. (1994) and Moreira et al. (2008).

According to some investigations, more testosterone is bound in the parotid gland than in the prostate or seminal vesicles, which largely depend on this hor- 
mone (Di Mangoni \& Stefano 1976). Importantly, testosterone stimulates the acini and salivary gland ducts to secrete growth factors such as EGF (Xu 2003) and neural growth factor (NGF) (Schneyer \& HumphreysBeher 1990). EGF binds to its receptor and activates an intrinsic tyrosine phosphorylation cascade leading to increased activity of phospholipase $\mathrm{C} \gamma$ and augmentation of intracellular $\mathrm{Ca}^{2+}$ levels due to the action of IP3 and PKC (Carpenter \& Cohen 1990). Furthermore, salivary gland cells are influenced by both EGF and TGF- $\alpha$ binding to a shared EGF-R. This shared EGF-R is a transmembrane protein with tyrosine kinase activity and it exerts trophic effects on salivary acinar, ductal and mucosal epithelial cells (Koski et al. 1997).

EGF influences the renewal and the growth of the acinar and ducts cells (Barthe et al. 1974, Walker et al. 1981). According to Barka et al. (2005), the gland cells express EGF and its receptors and EGF acts as an autocrine regulator in promoting growth and branching morphogenesis. Diminished expression of EGF and TGF- $\alpha$ in Sjogren's syndrome indicates a failure of this trophic system, which may contribute to the acinar atrophy and secondary changes, including atrophy of the oral mucosa (Koski et al. 1997).

Castration appears to influence the synthesis and distribution of androgen receptors in salivary glands that could further affect the function of the gland, diminishing secreted EGF levels (Li et al. 2005). There has been demonstration of this relationship working in the opposite direction. EGF also plays a physiological role in reproduction. Removal of the salivary gland in rodents reduces circulating EGF and the spermatogenesis process, which can be restored by EGF replacement (Wong et al. 2000).

In the present study we observed a significant reduction in EGF-R levels in the acute phase of Chagas disease as well as atrophy of acinar cells. Thus, it is possible that a decrease in EGF-R levels may be sufficient to induce histological and biochemical changes in the parotid gland during the acute phase of experimental Chagas disease. Interestingly, at 50 days of infection (chronic phase) body weight, testosterone levels and EGF-R expression returned to normal levels. In addition, no significant changes were observed in the histological aspect of parotid glands of infected rats. These results further suggest that morphological alterations in parotid glands are dependent on the testosterone-EGF-R axis. Future experiments using EGF-R antagonists are necessary to address this issue. Of note, normal rats treated with an EGF-R antibody presented a dose-dependent retardation of parotid gland proliferation (Purushotham et al. 1992).

In summary, these findings suggest that the testosterone-EGF-R axis is involved in morphological changes observed in parotid glands of rats with acute experimental Chagas disease. In addition, parotid glands show a normal histological aspect in the chronic phase, probably due to normalization of plasma testosterone levels, as this hormone is directly influenced by body weight.

\section{REFERENCES}

Alves JB, Machado CRS 1980. Histological and histoquantitative study of the rat submandibular gland in Chagas' disease. Arch Oral Biol 25: 437-443.
Alves JB, Napimoga MH, Araújo MS, Silva GAB 2008. Delay in maturation of the submandibular gland in Chagas disease correlates with lower DNA synthesis. Mem Inst Oswaldo Cruz 103: 585-590.

Barka T, Gresik ES, Miyazaki Y 2005. Differentiation of a mouse submandibular gland-derived cell line (SCA) grown on matrigel. Exp Cell Res 308: 394-406.

Barthe PL, Bullock LP, Nowsszowics I, Bardin CW, Orth DN 1974. Submaxillary gland epidermal growth factor: a sensitive index of biologic androgen activity. Endocrinology 95: 1019-1025.

Bradford MM 1976. A rapid and sensitive method for the quantification of microgram quantities of proteins utilizing the principle of protein dye binding. Anal Biochem 72: 248-254.

Brener Z 1962. Therapeutic activity and criterion of cure on mice experimentally infected with Trypanosoma cruzi. Rev Inst Med Trop Sao Paulo 4: 389-396.

Carpenter G, Cohen S 1990. Epidermal growth factor. J Biol Chem 265: 7709-7712.

Chagas C 1909. Nova tripanosomíase humana. Estudos sobre a morfologia e o ciclo evolutivo do Schizotrypanum cruzi n.g., n.s.p., agente etiológico de nova entidade mórbida no homem. Mem Inst Oswaldo Cruz 1: 159-218.

Courout M, Hochereau-de Reviers MT, Ortavant TR 1970. Spermatogenesis. In AD Johnson, WR Gomes, NL Van Denmark, The testis, Academic Press, New York, p. 339-431.

Di Mangoni S, Stefano C 1976. Le parotidi di ratto organo bersaglio per il testosterone. Boll Soc Ital Biol Sper 52: 397-403.

Jezek D, Banek L, Banek T 1996. Effects of orchiectomy on the rat parotid gland - an ultrastructural and stereological study. Acta Anat 155: 172-183.

Kasayama S, Ohba Y, Oka T 1990. Expression of epidermal growth factor gene in mouse lacrimal gland: comparison with that in the submandibular gland and kidney. J Mol Endocrinol 4: 31-36.

Köberle F 1968. Chagas disease and Chagas syndromes: the pathology of American trypanosomiasis. Adv Parasitol 6: 63-116.

Koski H, Konttinen YT, Hietanen J, Tervo T, Malmstrom M 1997. Epidermal growth factor, transforming growth factor - alpha and epidermal growth factor receptor in labial salivary glands in Sjogren's syndrome. J Rheumatol 24: 1930-1935.

Li HJ, Yao B, Liang W, Wang YM, Xu QL, Huang YF 2005. Localization and potential function of androgens receptor in rat salivary gland. Asian J Androl 7: 295-301.

Moreira A, Napimoga MH, Benatti BB, Silva GAB, Rocha-Rodrigues DB, Clemente-Napimoga JT, Vieira GA, Alves JB 2008. Morphological changes and EGF expression in the granular convoluted tubules cells of submandibular glands of Trypanosoma cruzi infected rats. Tissue Cell 40: 293-298.

Pereira SAL, Rodrigues DB, Ferraz MLF, Castro ECC, Reis MA, Paula ATV 2006. Inflammation and glandular duct dilatation of the tongue from patients with chronic Chagas disease. Parasitol Res 98: 153-156.

Purushotham KR, Dunn WA Jr, Schneyer CA, Humphreys-Beher MG 1992. A novel mechanism for isoprenaline-stimulated proliferation of rat parotid acinar cells involving the epidermal growth factor receptor and cell surface galactosyltransferase. Biochem $J$ 284: 767-776.

Schneyer CA, Humphreys-Beher MG 1990. Nerve growth factor - induced increase in [H3] thymidine incorporation into parotid and submandibular glands of young rats and its partial blockade by 
propranolol or partial sialoadenectomy. Biochem Pharmacol 39: $1679-1686$.

Silva LHP, Nussenzweig V 1953. Sobre uma cepa de Trypanosoma cruzi altamente virulenta para o camundongo branco. Folia Clin Biol 20: 191-208.

Silva RC, Cardoso JE, Silva GAB, Moreira A, Alves JB 2000. Histological and histoquantitative study of the rat parotid gland after Trypanosoma cruzi infection. Parasite 7: 109-113.

Tavares MCH, Carraro AA, Vianna Favaretto AL, Petenusci SO, Lopes RA, Ribeiro RD, Lamano Carvalho TL 1994. The male reproductive organs in experimental Chagas' disease. III. Plasma testosterone and accessory sex glands in the acute phase of the disease. Exp Toxicol Pathol 46: 243-246.

Vieira CB 1961. Hyperamylasemia and hyperactivity of salivary glands associated with megaesophagus. Am J Dig Dis 6: 727-741.

$\mathrm{Xu}$ QL 2003. The localization and potential function of androgen receptor mRNA in rat submaxillary. Zhonghua Nan Ke Xue 9: 681-683.

Walker P, Eichsel ME, Hoath SB, Poland RE, Fisher DA 1981. Effect of thyroxine testosterone and corticosterone on NGF and EGF concentrations in adult female mouse submaxillary gland: dissociation of NGF and EGF responses. Endocrinology 109: 582-587.

WHO - World Health Organization 2000. Who's certified. [database on the Internet]. Weekly Epidemiology Records c2000 [cited 2009 Feb 18]. Available from: http://www.who.int/wer/archives/en/.

Wong RW, Kwan RW, Mak PH, Mak KK, Sham M, Chan S 2000. Overexpression of epidermal growth factor induced hypospermatogenesis in transgenic mice. J Biol Chem 275: 18279-18301. 